\title{
Unscheduled apoptosis during acute inflammatory lung injury
}

\author{
Lin L. Mantell ${ }^{1}$, Jeffrey A. Kazzaz ${ }^{1}$, Jing $\mathrm{Xu}^{1}$, \\ Thomas A. Palaia ${ }^{2}$, Bruno Piedboeuf ${ }^{3}$, Stephen Hall ${ }^{4}$, \\ Gregory C. Rhodes ${ }^{5}$, Gang Niu ${ }^{1}$, Alan F. Fein ${ }^{1}$ and \\ Stuart Horowitz ${ }^{1}$
}

1 The CardioPulmonary Research Institute, Department of Medicine (Pulmonary and Critical Care), Winthrop-University Hospital, State University of New York at Stony Brook School of Medicine, Mineola, NY 11501, USA

2 Department of Medicine (Nephrology), Winthrop-University Hospital, State University of New York at Stony Brook School of Medicine, Mineola, NY 11501 USA

3 Department of Pediatrics (Neonatology), Centre de Recherche du C.H.U.L., Laval University, Sainte-Foy, Quebec, G1V 4G2, Canada

${ }^{4}$ Pulmonary and Critical Care Medicine, Oregon Health Sciences University, Portland, Oregon, 97201

${ }^{5}$ Barratt \& Smith Pathology, 7-9 Dora St, Orange, NSW 2800 Australia

${ }^{6}$ corresponding author: Stuart Horowitz, Ph.D. CardioPulmonary Research Institute, Winthrop-University Hospital, 222 Station Plaza North, Suite 604 Mineola, NY 11501, tel: 516-663-3917; fax: 516-663-8874 (8871); email: shorowit@winthrop.org

Received 15.12.96; revised 8.5.97; accepted 30.5.97

Edited by R. A. Lockshin

\begin{abstract}
Apoptosis is a mode of cell death currently thought to occur in the absence of inflammation. In contrast, inflammation follows unscheduled events such as acute tissue injury which results in necrosis, not apoptosis. We examined the relevance of this paradigm in three distinct models of acute lung injury; hyperoxia, oleic acid, and bacterial pneumonia. In every case, it was found that apoptosis is actually a prominent component of the acute and inflammatory phase of injury. Moreover, using strains of mice that are differentially sensitive to hyperoxic lung injury we observed that the percent of apoptotic cells was well correlated with the severity of lung injury. These observations suggest that apoptosis may be one of the biological consequences during acute injury and the failure to remove these apoptotic cells may also contribute to the inflammatory response.
\end{abstract}

Keywords: programmed cell death; necrosis; hyperoxia; oleic acid

Abbreviations: ALI, acute lung injury; TUNEL, Terminal transferase-dUTP-Nick-End Labeling; ICE, Interleukin-1 $\beta$ converting enzyme; DAPI, 4',6-diamidine-2-phenylindoledihydrochloride; IL-1 $\beta$, Interleukin-1 $\beta$; RNase, Ribonuclease

\section{Introduction}

Cell death is currently thought to occur via one of two distinct modes: apoptosis or necrosis. Apoptosis, also called programmed cell death, is the process of cellular self destruction and involves a specific series of events (Steller, 1995). It is often a scheduled and physiologically-regulated event, occurring during normal cell turnover, development, and in response to viral infection. In contrast, necrosis is the result of unscheduled, acute injury, and in vivo can result in or from an inflammatory response, which can be local or systemic (Thompson, 1995). When cells in tissue die via apoptosis, they are removed through phagocytosis by neighboring healthy cells (Steller, 1995). Thus, the observation that inflammation can be circumvented has given rise to the popular notion that apoptosis is a protective mode of cell death (Steller, 1995). Despite this paradigm, the question of whether apoptosis occurs during acute tissue injury in complex organs has not been addressed. We therefore studied acute injury in the lung, which is estimated to contain as many as 60 different cell types (Stone, 1992). Lung injury is known to be multifaceted, involving cascades of events that can be initiated by a wide variety of primary insults (Spragg, 1991). Acute lung injury (ALI) is usually accompanied and exacerbated by pulmonary inflammation. Because of the complex nature of $\mathrm{ALI}$, we hypothesized that cell death might be multimodal, involving not only necrosis (Spragg, 1991), but also apoptosis.

Oxygen $\left(\mathrm{O}_{2}\right)$ supplementation during mechanical ventilation in critically ill patients is often necessary to sustain life, yet supraphysiologic concentrations of $\mathrm{O}_{2}$ are toxic to cells and organs. Because the lungs are directly exposed, pulmonary $\mathrm{O}_{2}$ toxicity is a major complication of ventilation therapy. Animals exposed to hyperoxia suffer ALI, which is characterized by destruction of the alveolar-capillary barrier, leading to pulmonary edema, impaired gas exchange, and death in the worst cases (Crapo, 1978). Severe pneumonitis is a prominent feature of hyperoxic ALI. In preliminary studies, we showed that apoptosis occurs at a single time point in ALI from hyperoxia (Kazzaz, 1996). Here we examined apoptosis in three models of ALI: hyperoxia, oleic acid injury, and bacterial pneumonia.

\section{Results}

To study apoptosis during the development of hyperoxic ALI, we utilized the in situ TUNEL (Terminal transferase-dUTPNick-End Labeling) assay, which labels $3^{\prime}-\mathrm{OH}$ ends of DNA cut by endonucleases that are activated during apoptosis (Gavrieli, 1992; Tornusciolo, 1995). In a mouse model of hyperoxic lung injury, TUNEL-positive, apoptotic nuclei were clearly evident at a time when lung injury was severe, relative to control unexposed mice (Figure 1A). To independently 
confirm that the TUNEL assay was an accurate reflection of apoptosis in acutely-injured tissue, isolated genomic DNA from exposed and control lungs was studied. DNA isolated from apoptotic cells is visualized by agarose gel electrophoresis at $200 \mathrm{bp}$ ladders, which is a hallmark of apoptosis in nucleated cells (Leist, 1994; Wong, 1994). Figure 1B shows that acutely-injured hyperoxic lungs exhibited nucleosomal DNA ladders that are typical of apoptosis and that these ladders were not detected in control lung. Moreover, this response was not generalized to other organs that are not injured, since ladders were not evident in the liver DNA of the same animals (Figure 1B). In order to visualize DNA ladders it was necessary to first enrich for low molecular weight DNA with a single centrifugation step (Leist, 1994), as described in Materials and Methods. For this approach, an equal mass of injured or control tissue was subjected to the same fractionation scheme, and the low molecular weight fractions of each sample - which contained variable amounts of DNA depending on the extent of degradation - were loaded onto agarose gels. However, when equal masses of total, unfractionated cellular DNA were loaded, the ladders were not evident (Figure $1 \mathrm{C}$ ), suggesting that a relatively small proportion of the total genomic DNA was oligonucleosomesize length. Figure $1 \mathrm{C}$ also shows that the DNA samples examined did not suffer wholesale degradation.

Interleukin-1 $\beta$ converting enzyme (ICE) and other members of the ICE family of proteases have been shown to be activated in apoptosis. To determine if ICE upregulation occurs in hyperoxia-induced ALI, we examined the expression of ICE in untreated and hyperoxic mouse lungs. Figure 1D shows that ICE expression was induced in hyperoxic lungs relative to controls. In particular, the activated form of ICE, p20, was present exclusively in injured lung (Figure 1D).

The presence of apoptosis in acutely injured lung could be part of a protective mechanism to limit the extent of injury or inflammation, as has been proposed during resolution of acute respiratory distress syndrome (Polunovsky, 1993; Uhal, 1995). If apoptosis is also protective during acute lung injury, animals that are relatively resistant to such injury might be predicted to exhibit apoptosis sooner than sensitive animals. To examine this possibility, we utilized two inbred strains of mice that are differentially sensitive to acute hyperoxic ALI (Hudak, 1993; Piedboeuf, 1994). Previous studies (Hudak, 1993) indicated that C57BL/6J mice are relatively sensitive to lung injury by hyperoxia, when compared to another inbred strain, $\mathrm{C} 3 \mathrm{H} /$ HeJ. The sensitive C57/BL6J mice develop severe lung injury between 48 and $72 \mathrm{~h}$ of exposure to $100 \% \mathrm{O}_{2}$, and die shortly afterward. In contrast, $\mathrm{C} 3 \mathrm{H} / \mathrm{HeJ}$ mice show only mild lung injury after $72 \mathrm{~h}$ of exposure, as measured by the wet:dry lung weight ratios, and the protein content of broncho-alveolar lavages (Hudak, 1993). However, by $96 \mathrm{~h}$ the resistant mice also suffer severe lung injury, and demonstrate alveolar protein and wet: dry ratios similar to the sensitive strain $24 \mathrm{~h}$ earlier. This is paralleled by an identical shift in the timing of expression of lung injuryrelated genes (Hudak, 1993; Piedboeuf, 1994). Figure 2 shows that the extent of apoptosis was greater in the sensitive strain after 1 or 2 days of hyperoxia. Moreover, a quantitative analysis of fluorescent TUNEL assays indicates that in both strains there were large and significant
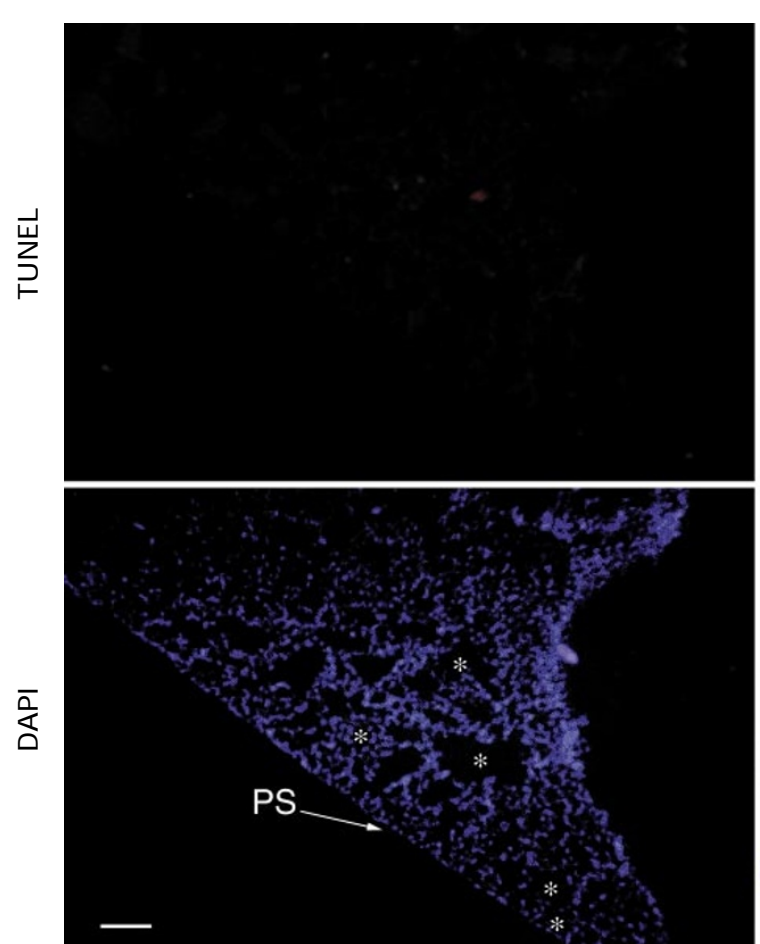

$72 \mathrm{~h} 100 \% \mathrm{O}_{2}$

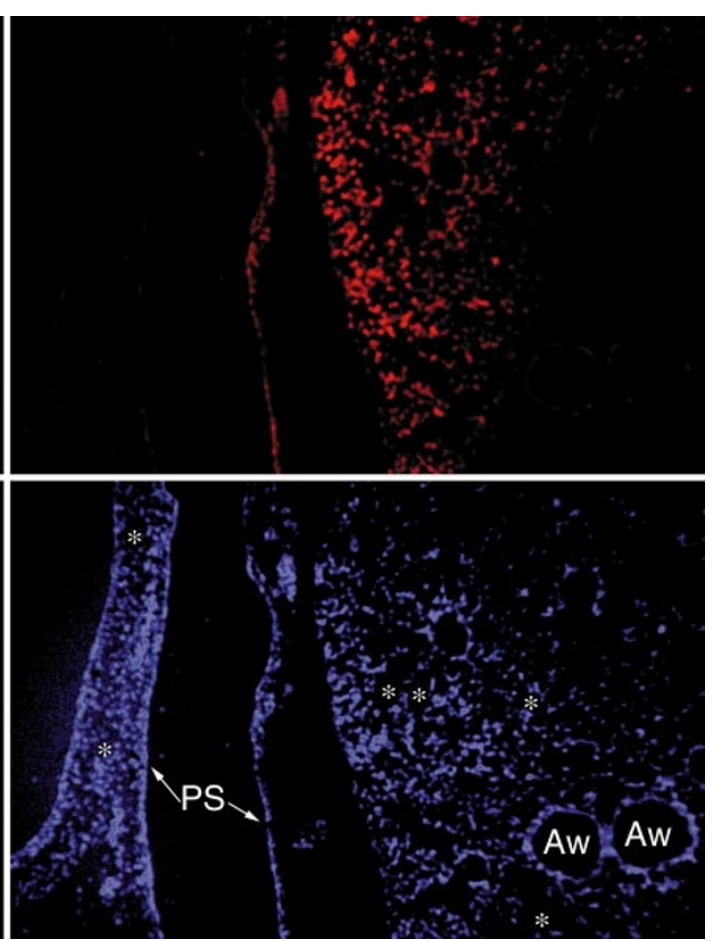


increases in the apoptotic index with advancing time in hyperoxia and that these increases occurred sooner in the sensitive strain. These data demonstrate that extent of apoptosis was well correlated with the severity of hyperoxic $\mathrm{ALI}$, and inversely correlated with resistance.

Term newborns of most species are relatively resistant to hyperoxia when compared to their adult (non-aged) counterparts. For example, adult rabbits do not survive exposure to $100 \% \mathrm{O}_{2}$ beyond $72 \mathrm{~h}$, while newborns survive for many days afterward. Overt ALI as assessed by the extent of pulmonary inflammation and edema is not evident in newborn rabbits until about $96 \mathrm{~h}$ of exposure, while adults are clearly injured by $48 \mathrm{~h}$ (Veness-Meehan, 1991). Figure 3 shows that apoptosis was prominent in hyperoxic adult rabbit lung much earlier than in newborns. As with the mice, increased length of exposure to hyperoxia resulted in more apoptosis (Figure 3), pulmonary inflammation
(Veness-Meehan, 1991), and overall, the extent of apoptosis was well correlated with the severity of lung injury.

Hyperoxia is a form of oxidant injury, and apoptosis is known to be induced by oxidative damage to cells (Slater, 1995). It therefore became important to determine if the induction of apoptotis was unique to hyperoxia, or could be generalized to other forms of ALI. Moreover, apoptosis was not evident in hyperoxic lungs until a day or more of oxygen exposure. Although apoptosis was widespread and appeared to involve many cell types in the lung, the timing of the onset and persistence of apoptosis was concurrent with the influx of neutrophils, which themselves are likely to undergo apoptosis during pulmonary inflammation. A commonly used model of $\mathrm{ALI}$ with a much more rapid onset involves the intravenous administration of oleic acid, which causes severe lung injury characterized by pulmon- b

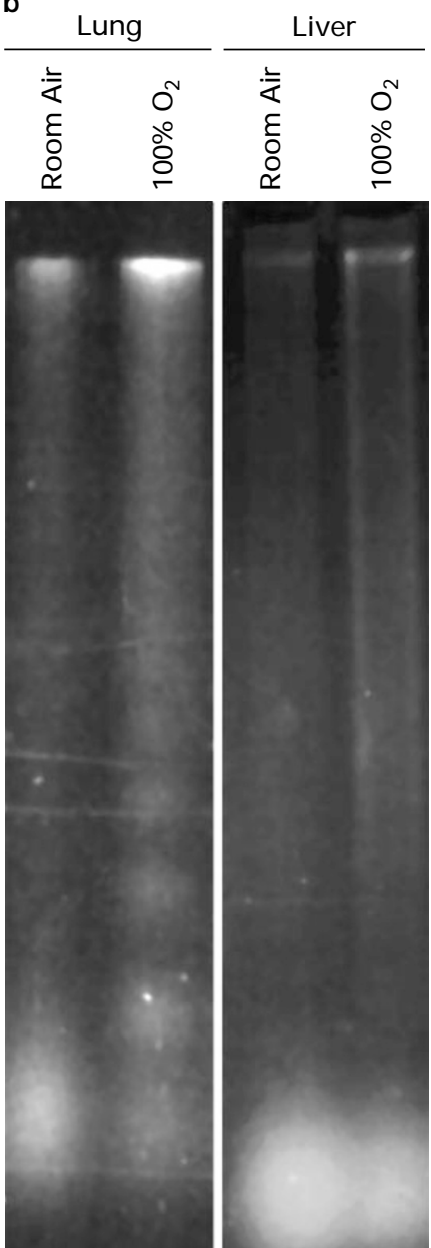

C

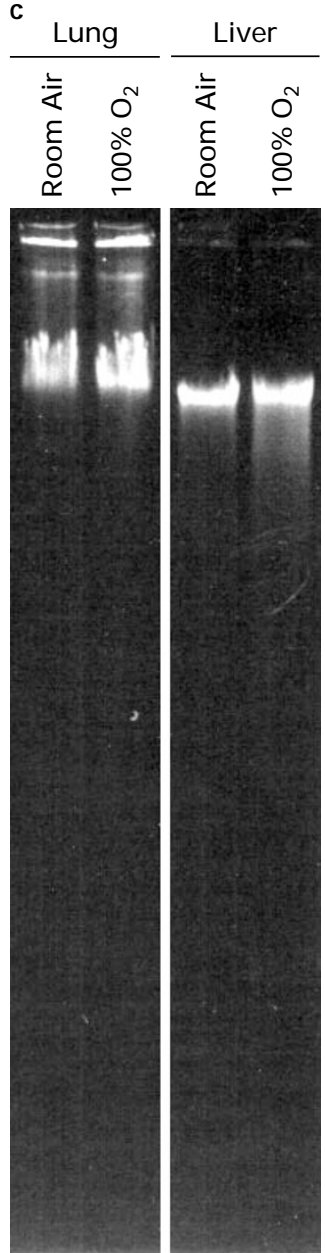

d

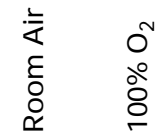

$45 \mathrm{kDa}-$

$20 \mathrm{kDa}-$
م̊요

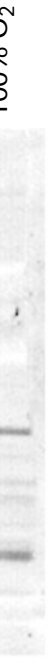

Figure 1 Apoptosis in the hyperoxic C57/BL6 mouse. (A) Photomicrographs of the fluorescent TUNEL assay performed on sections of lungs from control (room air) vs hyperoxic mice. The sections were also stained with DAPI to visualize all nuclei in the field. These results were typical at this time point (see quantitative analysis in Figure 2B). Scale bar represents $100 \mu \mathrm{m}$ in this and subsequent figures. PS - pleural surface of the lung lube, AW - airway, asterisks mark several alveoli. (B) Agarose gel of the low molecular weight fraction of genomic DNA. DNA was isolated from livers and lungs of control mice and mice exposed to $100 \% \mathrm{O}_{2}$ for $72 \mathrm{~h}$ and fractionated on $1 \%$ agarose gels. Results identical to those shown were obtained from five control and five hyperoxic $\mathrm{C} 3 \mathrm{H} / \mathrm{HeJ}$ and $\mathrm{C} 57 / \mathrm{BL} 6 \mathrm{mice}$. (C) Total cellular DNA from the same animals as in panel B. Two $\mu \mathrm{g}$ of DNA from each sample were loaded onto $1 \%$ agarose gels. The bulk of the DNA is shown to be intact, although liver DNA underwent minor degradation during isolation. (D) Western blot of nuclear extracts. Nuclear extracts were prepared from lungs of control mice and mice exposed to $100 \% \mathrm{O}_{2}$ for $72 \mathrm{~h}$, fractionated on $12 \%$ SDS - PAGE and probed for ICE 
ary edema, decreased pulmonary function, and fulminant inflammation (Schuster, 1994). Intravenous oleic acid produces an injury in rabbits with derangements in pulmonary physiology that are apparent within 5 min of infusion. By the end of $1 \mathrm{~h}$, a marked influx of polymorphonuclear leukocytes has occurred and the lungs are flooded by proteinaceous pulmonary edema (Hall, 1992). These changes are not observed in control animals given the vehicle alone. Oleic acid injury was distinct from hyperoxia in that the pattern of apoptosis was focal, correlating with patchy foci of injury known to occur in lung tissue in this model (Schuster, 1994). Thus, in a different model of ALI, where the insult is primarily vascular, apoptosis was also well correlated with severe lung injury (Figure 4). In this model, the timing of injury is too rapid to be attributable to dying neutrophils.

To test if apoptosis occurs during ALI of bacterial origin, we utilized a model of Streptococcal pneumonia. Rats infected with a bolus of Strep. sanguis develop acute and severe pneumonia over the course of one day (Rhodes, 1989). Figure 4 shows that apoptosis was evident in infected lungs as soon as $8 \mathrm{~h}$ post-infection. This early time point was clearly in the acute pneumonitic phase, a time of rapid influx of inflammatory cells, and well before the onset a
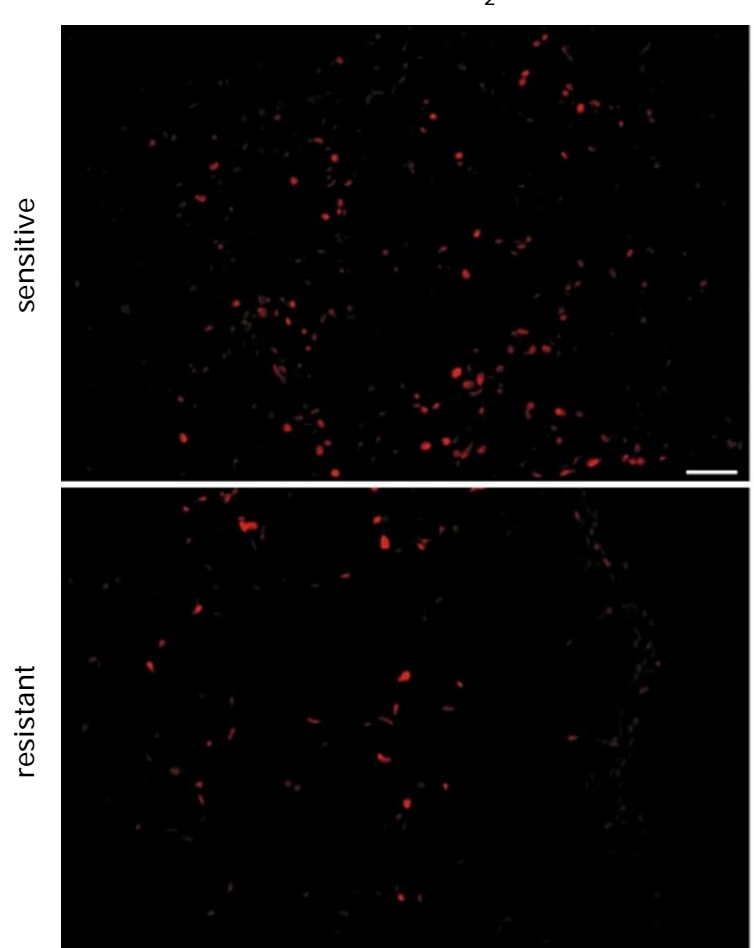

$48 \mathrm{~h} 100 \% \mathrm{O}_{2}$
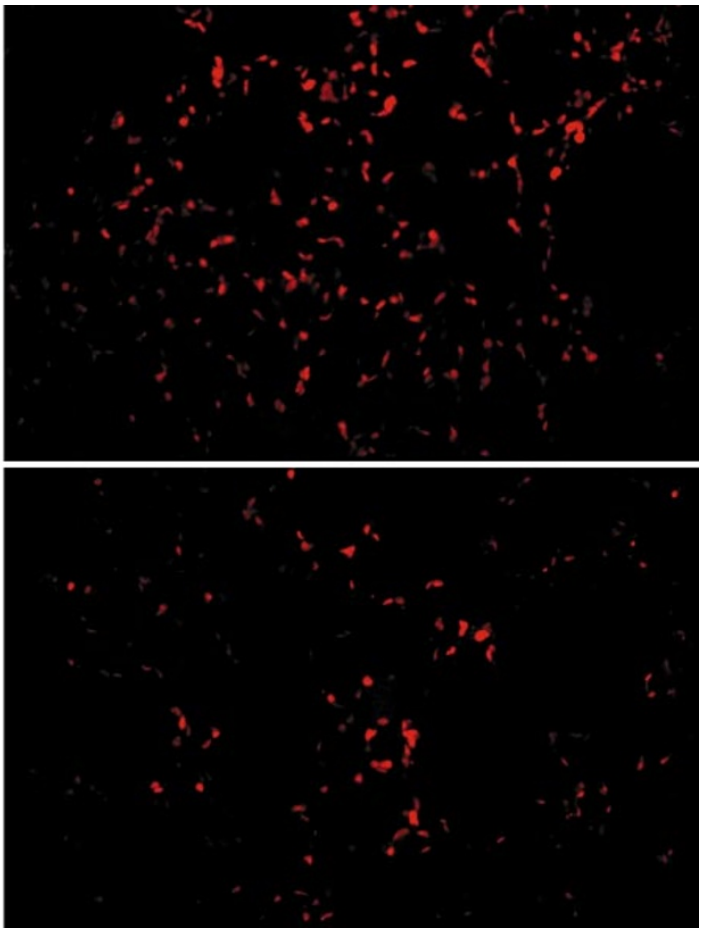

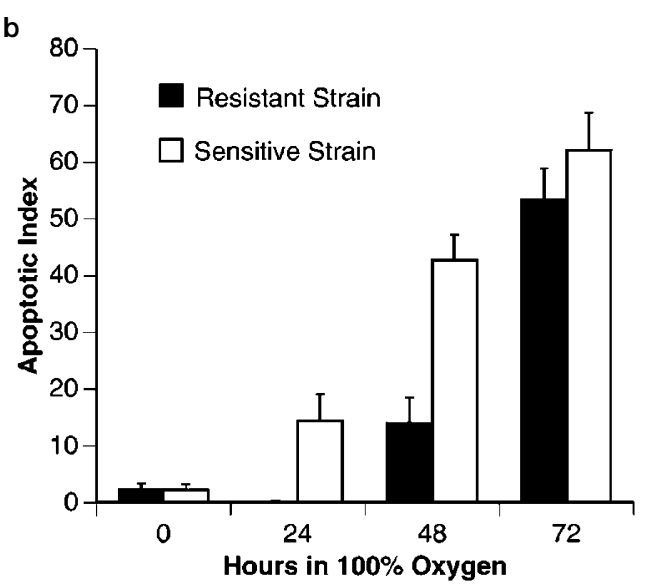

Figure 2 Apoptosis correlates with severe lung injury in $\mathrm{O}_{2}$-resistant vs $\mathrm{O}_{2}$-sensitive strains of mice. (A) Fluorescent TUNEL assays of lung sections from mice exposed to $100 \% \mathrm{O}_{2}$ for 24 and $48 \mathrm{~h}$. (B) Histogram of the apoptotic index of lung sections from normal and hyperoxic mice (10). Differences between strains and increases at $24 \mathrm{~h}$ and beyond within each strain were statistically significant $(P<0.05)$ 


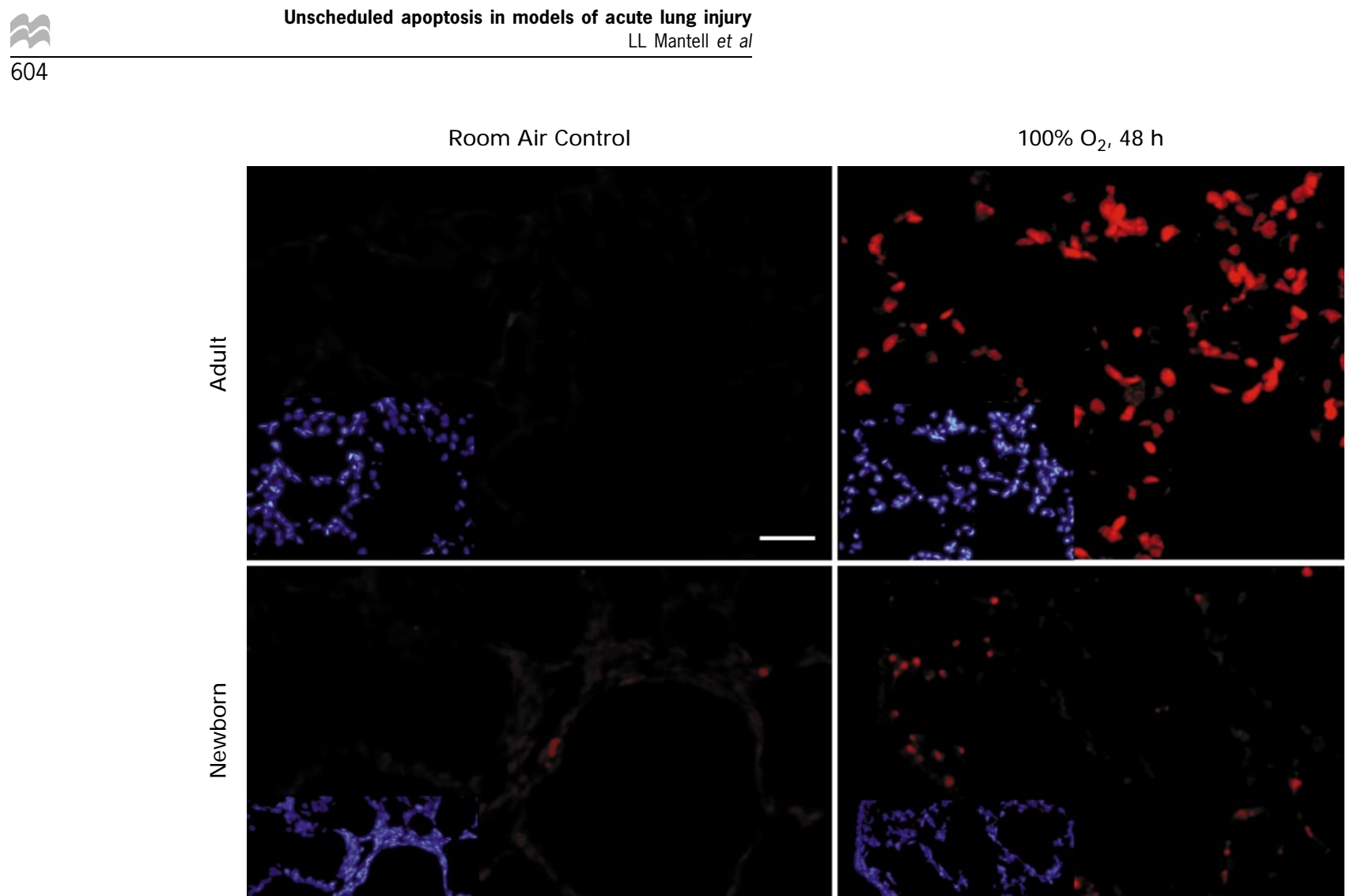

Figure 3 Apoptosis correlates with severe injury in the hyperoxic lungs of newborn and adult rabbits. Fluorescent TUNEL assays of lung sections from control and hyperoxic adult and newborn rabbits. Insets show DAPI fluorescence of the same sections
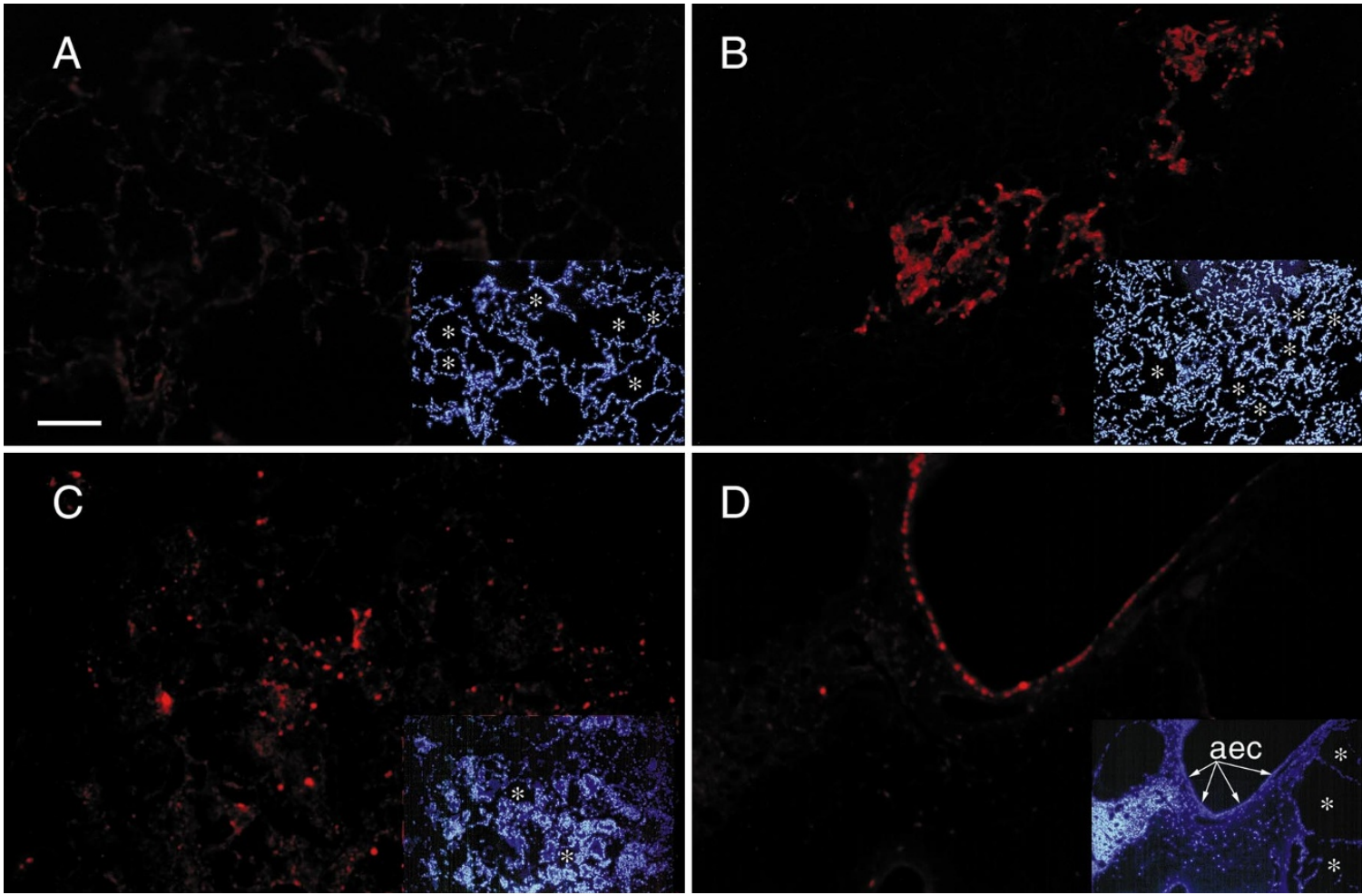

Figure 4 Apoptosis in other models of acute lung injury. Fluorescent TUNEL assays in control (A) and oleic injured (B) rabbit lungs, and rats with bacterial pneumonia (C and D). Insets show DAPI fluorescence of the same sections. Note the apoptosis in epithelial cells surrounding the large airway. Control rat lungs had virtually no TUNEL-positive cells (data not shown). Asterisks mark several alveoli, aec - airway epithelial cells 
of resolution of the infection (Rhodes, 1989). Apoptosis occurred during a time of severe pulmonary inflammation, as evident by DAPI (4',6-diamidine-2-phenylindole-dihydrochloride) fluorescence, which shows a large neutrophil infiltrate. Note that only a single cell of the infiltrate was TUNEL-positive at this phase of the infection. In contrast, apoptosis in nearby airway epithelial cells was prominent (Figure 4d).

\section{Discussion}

It has generally been thought that a distinguishing feature of apoptosis is that it occurs without eliciting an inflammatory response, while necrosis causes inflammation. Our data suggest this paradigm should be re-evaluated because it does not adequately account for our observations. Using three different models, we have found that apoptosis is clearly a feature of ALI. Moreover, the onset of ALI from oleic acid $(1 \mathrm{~h})$ is probably too short to allow for significant apoptosis of infiltrating neutrophils or macrophages, indicating that apoptosis occurred in lung cells. Even $8 \mathrm{~h}$ after infection of rat lungs with Strep. sanguis, the vast majority of inflammatory cells were TUNEL-negative, yet the airway epithelium was positive. Taken together with the observed widespread apoptosis in hyperoxic lung, we conclude that apoptosis occurs in lung parenchyma in these models of ALI. However, except for the obvious apoptosis in airway epithelium, it is difficult to definitively identify the cell types involved, especially in the gas exchange regions. Such identification requires electron microscopy or dual label methods (Piedboeuf, 1996) and awaits further study.

The finding that apoptosis is a prominent component of $A L I$ is not inconsistent with the concurrent existence of necrotic cell death in lung tissue. For example, capillary endothelial cells are thought to be the cell type most sensitive to hyperoxia in vivo, and are described as becoming swollen during hyperoxic injury (Fukuda, 1992), consistent with cell death via necrosis. Endothelial cell necrosis appears to be an early step in the cascade of lung injury, leading to pulmonary inflammation. Thus, apoptosis in acutely-injured lung may be a downstream phenomenon, occurring as a result of the release of mediators that are known to induce apoptosis in some systems, or oxidants released by inflammatory cells. Therefore, ALI probably involves multi-modal cell death, as can occur in injured liver (Ledda-Columbano, 1991). However, in these models of $\mathrm{ALI}$ the relative extent of apoptosis vs necrosis is not yet known.

Using image analysis to quantify apoptosis, we observed that during hyperoxia the severity of injury was well correlated with the extent of apoptosis. The simplest interpretation of these data is that apoptosis does not provide protection from hyperoxic ALI, because the more resistant animals had fewer apoptotic cells, relative to the sensitive animals. Alternatively, a protective role for apoptosis might have been impaired by the failue to effectively remove the dead cells during ALI, leading to inflammation. Regardless of the role of apoptosis during the acute and inflammatory phase, during repair from injury apoptosis appears to have an important and protective role in the removal of injured cells from lung (Polunovsky, 1993; Uhal, 1995). However, the occurrence of apoptosis in the early and inflammatory phase seems to have substantially different biological consequences than during repair.

Because the primary cause of ALI in humans is often unknown, it has been difficult to find effective therapeutic agents for these patients. Narrowly-targeted drugs are likely to affect only a fraction of those treated. The observation that apoptosis is a prominent component of ALI with vastly different etiologies suggests that strategies designed to intervene at a step in the apoptotic pathway may be useful in treating ALI. The molecular events that lead to apoptosis in lung are not yet known. In hyperoxic ALI, molecular $\mathrm{O}_{2}$ itself does not seem to be the stimulus, because cells exposed directly to hyperoxia in culture suffer necrosis, not apoptosis (Kazzaz, 1996). In addition, because capillary endothelial cell necrosis is an early sign of hyperoxic ALI (Crapo, 1978), it seems likely that apoptosis in ALI is a secondary or downstream event.

There is extensive evidence indicating that ICE and the ICE family of proteases play important roles in apoptosis (Takahashi, 1995; Kuida, 1996), although each member of the family may have a direct impact on apoptosis in different types of cells or in different tissues, and during different stages of development (Kuida, 1996). Upregulation of ICE expression in hyperoxic mouse lung indicates that this apoptotic pathway is activated in pulmonary oxygen toxicity. Interestingly, the ICE family of proteases are involved in the progression of apoptosis, yet IL-1 $\beta$ (Interleukin-1 $\beta$ ) is a pro-inflammatory protein, which is activated by ICE. Consistent with this is the observation that in the models we studied, apoptosis was prominent at and after the onset of inflammation. It thus seems likely that apoptosis during acute tissue injury is probably not limited to lungs. Ischemia-reperfusion injury of the heart is known to cause myocardial apoptosis (Gottlieb, 1994), and this injury also has a strong inflammatory component (Das, 1993). Further work is necessary to elucidate the mediators of apoptosis that function in a milieu of acute inflammation.

\section{Materials and Methods}

\section{TUNEL assays and photomicrography}

Tissue sections $(4-5 \mu \mathrm{m})$ were mounted onto slides pretreated with 3aminopropylethoxysilane (Digene Diagnostics, Inc., Beltsville, MD), Slides were baked for $30 \mathrm{~min}$ at $60^{\circ} \mathrm{C}$ and washed twice in fresh xylenes for $5 \mathrm{~min}$ each to remove paraffin. The slides were rehydrated through a series of graded alcohols then washed in distilled water for 3 min. Terminal transferase-dUTP-Nick-End Labeling (TUNEL) assays were as described (Tornusciolo, 1995) except that all reagents were obtained from Boehringer Mannheim (Indianapolis, IN). Tissue sections were counterstained with $2 \mu \mathrm{g} / \mathrm{ml}$ 4',6-diamidine2-phenylindole-dihydrochloride (DAPI) for $10 \mathrm{~min}$ at room temperature. Photomicrographs were recorded on $35 \mathrm{~mm}$ film using a Nikon Optiphot microscope and UFX camera system (Nikon Inc., Melville, $\mathrm{NY}$ ) and transferred onto a Kodak PhotoCD. The images were digitally adjusted for contrast using Adobe Photoshop 3.0.5 (Adobe Systems Inc., Mountain View, CA). 


\section{Exposure of mice and rabbits to hyperoxia}

Mice were placed in Plexiglass chambers and exposed to $100 \% \mathrm{O}_{2}$. Mice were sacrificed by cervical dislocation, the lungs were fixed by installation of $10 \%$ formalin, and embedded into paraffin as described previously (Piedbouef, 1994).

Adult and day-old newborn New Zealand White rabbits were placed in Plexiglass chambers and exposed to $100 \% \mathrm{O}_{2}$ as previously described (Veness-Meehan, 1991). Control adults were unexposed and control newborns were reared and fed identically, but in room air (Veness-Meehan, 1991). After sacrifice by lethal injection of sodium pentobarbital, the lungs were fixed and embedded in paraffin as described previously (Veness-Meehan, 1991).

\section{Isolation of DNA ladders}

For visualization of DNA ladders, $\mathrm{C} 3 \mathrm{H} / \mathrm{HeJ}$ and $\mathrm{C} 57 / \mathrm{BL} 6$ mouse lung and liver tissues were removed immediately upon sacrifice, sliced, frozen in liquid $\mathrm{N}_{2}$ and stored at $-80^{\circ} \mathrm{C}$. The low molecular-weight fraction of DNA was isolated as described previously (Leist, 1994) with the following modifications: after homogenization of equal masses of tissue, and centrifugation at $13000 \times g$ to separate the low and high molecular weight fractions of genomic DNA, the supernatant (low molecular weight fraction) was digested first with ribonuclease (RNase, $100 \mu \mathrm{g} / \mathrm{ml})$ then with proteinase $\mathrm{K}(90 \mu \mathrm{g} / \mathrm{ml})$; both at $37^{\circ} \mathrm{C}$, for $30 \mathrm{~min}$. Samples were extracted with phenol, and phenol:chloroform (1:1), and ethanol precipitated. Resulting DNA samples were dissolved in equal volumes and separated by electrophoresis on $1 \%$ agarose gels, then stained with $0.5 \mu \mathrm{g} / \mathrm{ml}$ Ethidium Bromide. Total cellular DNA was extracted as described (Ausubel et al, 1997) and also run on agarose gels.

\section{Western blot analysis of interleukin- $1 \beta$ converting enzyme}

$\mathrm{C} 3 \mathrm{H} / \mathrm{HeJ}$ and $\mathrm{C} 57 / \mathrm{BL} 6$ mouse lung and liver tissues were obtained as describe above. Tissues were homogenized in hypotonic buffer containing $50 \mathrm{mM}$ Tris-Cl pH 7.5 and protease inhibitors (1 mM PMSF and $10 \mu \mathrm{g} / \mathrm{ml}$ Aprotinin). Nuclear extracts were obtained after the homogenates were sedimented at $13000 \times g$ for $15 \mathrm{~min}$. Ten $\mu \mathrm{g}$ total protein was resolved by $12 \%$ SDS-PAGE and proteins were transferred to an immobilon-P transfer membrane (Millipore Corporation, Bedford, MA) in a blotting buffer containing $25 \mathrm{mM}$ Tris, $192 \mathrm{mM}$ glycine and $20 \%$ methanol. Nonspecific antibody binding was blocked by incubating the membrane with $5 \%$ nonfat dried milk, $0.1 \%$ Tween 20 in phosphate-buffered saline. The membrane was incubated with polyclonal anti-ICE (M-20) antibody (Santa Cruz Biotechnology Inc., Santa Cruz, CA) and then with alkaline phosphatase conjugated antirabbit antibodies (Boehringer Mannheim, Indianapolis, IN). The staining was visualized by incubating with nitro blue tetrszolium chloride (NBT) and 5-bromo-4-chloro-3-indolylphosphate (BCIP) (Boehringer Mannheim, Indianapolis, IN).

\section{Computer aided image analysis}

To quantify the extent of apoptosis in the mouse lung, samples were illuminated with UV-light to visualize either TUNEL-positive-nuclei $(590 \mathrm{~nm})$ or total, DAPI-stained nuclei $(420 \mathrm{~nm})$. Images were captured with a CCD video camera. Uniform camera control settings were used for image capture and image thresholding was identical for all images. The captured images were analyzed using the Image 1 system (Universal Imaging, West Chester, PA) running on a personal computer. At least 25 fields were analyzed from at least two individuals at each time point. The apoptotic index was calculated as the percent of TUNEL-positive apoptotic nuclei divided by the DAPI-staining nuclei. The data were analyzed for statistical significance using the Student's T-test and ANOVA.

\section{Oleic acid injury model}

New Zealand White rabbits were anesthetized, ventilated, and administered an intravenous injection either of oleic acid or saline alone, as previously described (Hall, 1992). After $1 \mathrm{~h}$ the animals were killed by exsanguination, the lungs were fixed and embedded as described above. Identical results were obtained in three of three independent experiments.

\section{Induction of pneumonia in rats}

Inocula of Strep. sanguis were introduced into the left main bronchus of pathogen free Wistar rats as described previously (Rhodes, 1989). After $8 \mathrm{~h}$, the animals were killed by exsanguination, the lungs were fixed and embedded in paraffin as described previously (Rhodes, 1989). Identical results were obtained in five of five independent experiments.

\section{Acknowledgements}

We thank Dr. P.B. Bitterman (University of Minnesota) for his comments and suggestions on this manuscript. This work was supported in part by Basic Research Grant \#1-FY96-0752 from The March of Dimes Birth Defects Foundation, the American Lung Association of Nassau-Suffolk, and grants from the PHS, Winthrop Eager Breathers, and WinthropUniversity Hospital.

\section{References}

Ausubel FM, Brant R, Kingston RE, Moore DD, Seidman JG, Smith JA and Struhl K (1997) Current Protocols in Molecular Biology on CD ROM. New York: John Wiley \& Sons

Crapo JD, Peters-Golden M, Marsh-Salin J and Shelburne JS (1978) Pathologic changes in the lungs of oxygen-adapted rats: a morphometric analysis. Lab. Invest. 39: 640-653

Das DK (1993) Pathophysiology of reperfusion injury. Boca Raton: CRC Press, Inc.

Fukuda Y, Herman EH and Ferrans VJ (1992) Effect of ICRF-187 on the pulmonary damage induced by hyperoxia in the rat. Toxicology 74: 185-202

Gavrieli Y, Sherman Y and Ben-Sasson SA (1992) Identification of programmed cell death in situ via specific labeling of nuclear DNA fragmentation. J. Cell Biol. 119: 493-501

Gottlieb RA, Burleson KO, Kloner RA, Babior BM and Engler RL (1994) Reperfusion injury induces apoptosis in rabbit cardiomyocytes. J. Clin. Invest. 94: 16211628

Hall SB, Lu RZ, Venkitara AR, Hyde RW and Notter RH (1992) Inhibition of pulmonary surfactant by oleic acid. J. Appl. Physiol. 72: 1708-1716

Hudak B, Zhang L and Kleeberger S (1993) Inter-strain variation in susceptability to hyperoxic injury of murine airways. Pharmacogenetics 3: 135-143.

Kazzaz JA, Xu J, Palaia TA, Mantell L, Fein AM and Horowitz S (1996) Cellular oxygen toxicity - oxidant injury without apoptosis. J. Biol. Chem. 271: $15182-15186$

Kuida K, Zheng TS, Na S, Kuan C, Yang D, Karasuyama H, Rakic P and Flavell RA (1996) Decreased apoptosis in the brain and premature lethality in CPP32deficient mice. Nature 368-372.

Ledda-Columbano G, Coni P, Curto M, Giacomini L, Faa G, Oliverio S, Piacentini M and Columbano $A$ (1991) Induction of two differentmodes of cell death, apoptosis and necrosis, in rat liver after a single dose of thioacetamide. American Journal of Pathology 139: 1099-1109 
Leist M, Gantner F, Bohlinger I, Germann PG, Tiegs G and Wendel A (1994) Murine hepatocyte apoptosis induced in vitro and in vivo by TNF- $\alpha$ requires transcriptional arrest. J Immunol. 153: 1778-1788

PiedboeufB, Frenette J, Petrov P, Welty SE, Kazzaz JA and Horowitz S (1996) In vivo expression of intercellular ashesion molecule 1 in type II pneumocytes during hyperoxia. Am. J. Respir. Cell Mol. Biol. 15: 71-77

Piedboeuf B, Johnston C, Watkins R, Hudak B, Lazo J, Cherian M and Horowitz S (1994) Increased expression of tissue inhibitor of metalloproteinases (TIMP-1) and metallothionein in murine lungs after hyperoxic exposure. Am. J. Respir. Cell Mol. Biol. 10: 123-132

Polunovsky VA, Chen B, Henke C, Snover D, Wendt C, Ingbar DH and Bitterman PB (1993) Role of mesenchymal cell death in lung remodeling after injury. J. Clin. Inves. 92: 388-397

Rhodes GC, Tapsall JW and Lykke AWJ (1989) Alvoelar epithelial responses in experimental streptococcal pneumonia. J. Pathol. 157: 347-357

Schuster DP (1994) ARDS: Clinical lessons from the oleic acid model of acute lung injury. Am. J. Respir. Crit. Care Med. 149: 245-260

Slater AFG, Nobel CSI and Orrenius S (1995) The role of intracelllar oxidants in apoptosis. Biochim. Biophys. Acta-Molecular Basis of Disease 1271: 59-62

Spragg RG and Smith RM (1991) Biology of lung injury. The lung: Scientific foundations (eds.) RG Crystal and JB West. New York: Raven Press, Ltd

StellerH(1995) Mechanisms and genes of cellular suicide. Science 267: 1445-1449
Stone KC, Mercer RR, Gehr P, Stockstill B and Crapo JD (1992) Allometric relationships of cell numbers and size in the mammalian lung. Am. J. Respir. Cell. Mol. Biol. 6: 235-243

Takahashi C, Harada Y, Ariga H and Iguchiariga SMM (1995) Involement of pim-1 in DNA fragmentation in mouse NS-1-derived cells. Biochem. Biophys. Res. Commun. 215: 538-546

Thompson CB (1995) Apoptosis in the pathogenesis and treatment of disease. Science 267: 1456-1462

Tornusciolo DRZ, Schmidt RE and Roth KA (1995) Simultaneous detection of TdTmediated dUTP-Biotin nick end labeling (TUNEL)-positive cells and multiple immunohistochemical markers in single tissue sections. Biotechniques 19: $800-805$

Uhal BD, Joshi I, True AL, Mundle S, Raza A, Pardo A and Selman M (1995) Fibroblasts isolated after fibrotic lung injury apoptosis of alveolar epithelial cells in vitro. Am. J. Physiol.-Lung Cellular and Molecular Physiology 13: L819-L828

Veness-Meehan KA, Cheng ERY, Mercier CE, Blixt SL, Johnston CJ, Watkins RH and Horowitz S (1991) Cell-specific alteration in expression of hyperoxiainduced messenger RNAs of lung. Am. J. Respir. Cell Mol. Biol. 5: 516-521

Wong P, Smith SB, Bora N and Gentleman S (1994) The use of COt-1 probe DNA for the detection of low levels of DNA fragmentation. Biochem. Cell Biol. 72: 649653 